\title{
To Be or Not to Be: Parents' Willingness to Send Their Children Back to School After the COVID-19 Outbreak
}

\author{
Zehui Zhan ${ }^{1}$ (1) $\cdot$ Yuanmin $\mathrm{Li}^{1} \cdot$ Xinyue Yuan $^{1} \cdot$ Qi Chen $^{1}$
}

Accepted: 29 July 2021/Published online: 5 August 2021

(C) De La Salle University 2021

\begin{abstract}
This study investigated the factors that parents considered when sending their children back to school after the COVID-19 outbreak and analyzed the dilemma that parents were facing. A total of 1067 questionnaires were collected through snowball sampling. After three levels of coding based on Grounded Theory and Field Theory, parents' key concerns were categorized as four personal factors (i.e., intuitive expectation, health issue, learning effectiveness, perceived epidemic safety) and three environmental factors (i.e., school environment, family environment, social environment). By factor weight analysis using the Kruskal-Wallis $\mathrm{H}$ test, a field model of factors that affect parents' willingness was set up. Results indicated that learning effectiveness is the most critical factor affecting parents' willingness. By considering both personal and environmental factors, most parents were not satisfied with the effect of home-based online education and expressed their willingness to send their children back to school and resume classes; however, they also worried about students' epidemic awareness and self-protection abilities. Students' development highly depends on the social atmosphere, a regular schedule, and environmental support from schools, which can hardly be achieved by home-based online learning. The findings suggest that the joint efforts of society, schools, and families are needed on the issue of students returning to school after the COVID19 outbreak.
\end{abstract}

Zehui Zhan

zhanzehui@m.scnu.edu.cn

1 School of Information Technology in Education, South China Normal University, Guangzhou 510631, China
Keywords COVID-19 - Willingness to resume classes · Field Theory · Online education · Learning effectiveness

\section{Introduction}

As reported by UNESCO, there are 1.5 billion (84.8\%) students in 172 countries around the world who have been affected by the school closure caused by the COVID-19 epidemic. China was one of the first countries to take action by launching the plan of "Disrupted classes, undisrupted learning" (Huang et al., 2020) to provide more than 270 million students with flexible online learning at home (Zhong \& Zhan, 2020). Similarly, schools in the United Kingdom also distributed learning resources through the internet to allow students to continue their courses at home (Kidd \& Murray, 2020). It has become a common consensus that students should not stop receiving education during the epidemic. However, hundreds of millions of educators and learners have to face the choice of whether students should stay at home and study online or return to school before COVID-19 is over. It is necessary to know more about how students and their parents really think about home-based learning during the COVID19 outbreak and their opinions on resuming classes. Only by understanding their preferences and concerns can we directly hit the "internal problems", so as to provide better services and improve the educational system during the epidemic.

This paper explores the parents' attitudes and motivation related to students' return to school after the outbreak of COVID-19 and analyzes the reasons behind the change in parents' attitudes, so as to explore various factors affecting students' learning and growth during COVID-19. We conducted a questionnaire survey on over a thousand 
Chinese parents and comprehensively analyzed the reasons behind the change in parents' willingness according to Grounded Theory and Field Theory. On the one hand, we deeply reflected on the problems of home-based learning during the epidemic period, especially the advantages and disadvantages of large-scale online teaching. On the other hand, we also explored the potential direction of school adjustment in the post-epidemic era. This will provide a powerful reference for countries where the epidemic situation is still severe and will help them to consider resuming classes in advance (Dong et al., 2020).

\section{Literature Review}

\section{Parents' Attitude Toward Learners' Returning to School After the COVID-19 Outbreak}

In the post-epidemic era, as the epidemic situation gradually stabilizes, the problem of resuming classes would follow (Betz, 2020). Early psychological studies have shown that long-term isolation can harm the growth of children (Capurso et al., 2020), including triggering anxiety, fear, and other behavioral problems (Jiao et al., 2020; Zhan et al., 2021a). Therefore, the issue of students resuming classes is particularly important. Because of isolation at home during the epidemic, children get along more closely with their parents, and so the attitude of parents toward their children's return to school is particularly important (Downes et al., 2020). Many factors affect parents' attitudes toward students' return to school, including learning effects, school atmosphere, family supports, and so forth (Garbacz et al., 2016).

A previous study on students' willingness to return to school showed that $31 \%$ of parents wanted to keep their children at home, while $49 \%$ wanted to send their children back to school. Whether to send a child back to school is related to confidence in the school, the challenges of home learning, and parents' work factors (Hageman, 2020). In a questionnaire survey in Texas, it was found that more than half of parents supported their children's return to school to receive traditional face-to-face education. At the same time, concerns about student health and safety are the most important factors when considering returning to school (Limbers, 2021). The British government announced that from June 1, 2020, students in the first and sixth grades could return to school in stages. However, this decision was strongly opposed by parents and the media, since they felt anxious and worried about the students' safety (Khattab et al., 2020). Parents' concerns about their children's health and safety are the most important factor when considering their children's return to school (Limbers, 2021).

\section{Field Theory}

According to Gestalt psychology, individuals' behavior is the final comprehensive product of their current environment and how individuals view it (Marrow, 1969). Based on this, Lewin (1939) set up a function to indicate an individual's life space by a collection of interdependent factors: $B=f(P E)=f(L S)$, where $B$ represents behavior, $f$ represents functional relationship, $\mathrm{P}$ represents person, $\mathrm{E}$ represents environment, and LS represents life space (Eysenck \& Lewin, 1952). Life space is used to express the psychological power generated by the interaction between individuals and the environment, so as to explore the factors that affect people's behaviors (Back, 1992; Burnes, 2007). As a psychological analysis method, Field Theory emphasizes the construction of life space models. It believes that due to the continuous interaction of various elements in the field, the behavior system of people and groups is always fluctuating, while maintaining a relatively stable state, the "quasi-stationary equilibrium" state (Lewin, 1939).

The understanding and explanation of things are all for the purpose of finally taking effective action (Argyris, 1997). In the analysis of life space, the most important point is to understand the various forces that affect behavior, and to ultimately control and adjust these forces according to the purpose of the action. By the 1990s, force field analysis, a variant of Field Theory, was widely used as a tool for evaluating organizational change (Burnes \& Cooke, 2012). Brager and Holloway (1993) pointed out that, when analyzing the psychological field, we can find that there are two different forces that psychologically influence behavior: one is driving force, which is composed of variables that change behavior and support the change of plan, and the other is restraining force, which is composed of variables that resist the change of action. Through the analysis of driving force and restraining force, we can realize the systematic analysis, prediction, and adjustment of behavior change.

\section{Purpose of the Current Study}

During the COVID-19 epidemic, schools all over the world are facing similar challenges related to resuming classes. The current study aimed to investigate parents' willingness to send their children back to school after the epidemic, exploring the factors that were of most concern to parents. Therefore, there were two research questions proposed in this study: (1) How willing were the parents to return their children to school? and (2) What are the reasons underlying their willingness/unwillingness? Of course, we were also curious about how parents think about the effects of their 
children studying at home during the epidemic, to bring further enlightenment to the investigation. For schools in the districts where the epidemic is still severe, the findings of this study may provide necessary information, and help them consider the issue of resuming classes in advance (Dong et al., 2020).

\section{Method}

\section{Participants}

The participants in this study were 1392 K-12 students' parents from Guangdong Province, a region in China with a relatively developed economy. We excluded 325 questionnaires that did not include meaningful opinions or which were left blank. The remaining 1067 survey data (including 20 kindergarten parents, 886 elementary school parents, and 161 middle school parents) were complete and valid, and thus, they were finally used for coding and analysis.

\section{Questionnaire}

By the end of April 2020, China's COVID-19 outbreak had been effectively controlled. The questionnaire was distributed on April 28, 2020 and returned on April 29, 2020. Before the questionnaire was distributed, the government policy encouraged schools to organize students to return to school and resume classes from April 27, 2020. There were four items in the questionnaire: (1) the identity of the participants; (2) the school district in which the participants' children attended school; (3) the degree of willingness for their children to return to school (i.e., a 5-point Likert scale ranging from $1=$ "very reluctant for their children to return to school" to $5=$ "very willing for their children to return to school"); and (4) the reasons why they would or would not like their children to go back to school (i.e., open-ended question to fill in).

\section{Coding Process}

First, the parents' willingness to send their children back to school after the COVID-19 outbreak was assigned a weight according to the Likert 5-level scale (i.e., strongly willing $=+2$, quite willing $=+1$, no tendency $=0$, quite unwilling $=-1$, and strongly unwilling $=-2$ ). Secondly, the parents' opinions that were reported in the open-ended question were coded based on Grounded Theory (Strauss \& Corbin, 1998), and under the guidance of Field Theory. The open coding, axial coding, and selective coding were adopted in turn.
In selective coding, based on Field Theory, the key factors affecting parents' willingness for their children to go back to school were extracted. In the open coding procedure, the parents' open answers in the questionnaire were labeled by two researchers, respectively, and 19 frequently appearing labels such as mental health, visual health, physical exercise, and learning environment were obtained. Then the labels with similar meanings were classified and merged, and seven categories: intuitive expectation, health issue, learning effectiveness, perceived epidemic safety, school environment, family environment, and social environment, were extracted. The coding consistency of the two researchers was calculated using kappa calculation, kappa $=0.89$; as it was greater than 0.8 , it indicates that the coding had high consistency. In the axial coding procedure, these two researchers negotiated the coding based on Field Theory, and finally classified these seven categories into two main categories: personal factors and environmental factors. In the coding process based on Grounded Theory, we established a systematic connection between factors and categories, thereby constructing a theoretical framework to indicate parents' willingness to send their children back to school after the COVID-19 outbreak, as shown in Table 1.

\section{Data Analysis}

This is a mixed-method research study adopting both qualitative and quantitative analysis. First of all, the Grounded Theory was used to analyze the content of the open-ended questions about the reasons behind the willingness mentioned by the parents in the questionnaire, and key factors affecting parents' willingness were extracted under the guidance of Field Theory. Through descriptive statistics, the weight of parents' willingness corresponding to these factors was analyzed. The Kruskal-Wallis $\mathrm{H}$ test was used to compare the factor loadings of parents' concerns. Then, linking back to Field Theory, the driving force and restraining force among factors were differentiated, so as to understand how different factors affect parents' willingness.

\section{Results}

\section{Descriptive Analysis of Parents' Willingness}

Table 2 presents the degree of willingness reported by parents using the Likert scale. As can be seen, most parents in the survey were willing to let their children return to school. Only $15 \%$ of parents were unwilling or strongly unwilling to return their children to school. 
Table 1 Classification of factors affecting the parents' willingness to send their children back to school

\begin{tabular}{|c|c|c|c|}
\hline Categories & $\begin{array}{l}\text { First-level } \\
\text { indicators }\end{array}$ & Second-level indicators & Example \\
\hline \multirow{12}{*}{$\begin{array}{l}\text { Personal } \\
\text { factors }\end{array}$} & \multirow{2}{*}{$\begin{array}{l}\text { Intuitive } \\
\text { expectation }\end{array}$} & Expecting a return school & "My kid is eager to return to school and play with his classmates" \\
\hline & & $\begin{array}{l}\text { Expecting a return to } \\
\text { normal life }\end{array}$ & $\begin{array}{l}\text { "I myself want to return to a normal life. I need to work rather than be a baby- } \\
\text { sitter at home", "We need a normal life" }\end{array}$ \\
\hline & \multirow[t]{4}{*}{ Health issue } & Mental health & "Children would feel depressed when cooped up at home every day" \\
\hline & & Vision health & "Online courses could lead to myopia" \\
\hline & & Physical exercise & "Staying at home prevents the children from getting necessary exercise" \\
\hline & & Regular schedule & $\begin{array}{l}\text { "It is difficult to have a regular daily schedule when staying at home, which is } \\
\text { not good for kids' development" }\end{array}$ \\
\hline & \multirow{3}{*}{$\begin{array}{l}\text { Learning } \\
\text { effectiveness }\end{array}$} & Academic performance & "Poor quality of online courses; The effect of learning at school is better" \\
\hline & & Learning efficiency & "Children's attention and self-consciousness are difficult to achieve at home" \\
\hline & & Learning systematically & $\begin{array}{l}\text { "Children can obtain knowledge systematically at school, while they only learn } \\
\text { fragmentally at home" }\end{array}$ \\
\hline & \multirow{3}{*}{$\begin{array}{l}\text { Perceived } \\
\quad \text { epidemic } \\
\quad \text { safety }\end{array}$} & $\begin{array}{l}\text { Trouble caused by epidemic } \\
\text { prevention }\end{array}$ & $\begin{array}{l}\text { "Kids need to wear a mask for the whole day at school, which might make them } \\
\text { very uncomfortable" }\end{array}$ \\
\hline & & $\begin{array}{l}\text { Awareness and ability of } \\
\text { epidemic self-protection }\end{array}$ & "Kids are too young to protect themselves" \\
\hline & & Student safety & "Children's safety is the most important thing" \\
\hline \multirow{7}{*}{$\begin{array}{l}\text { Environmental } \\
\text { factors }\end{array}$} & \multirow{3}{*}{$\begin{array}{l}\text { School } \\
\text { environment }\end{array}$} & Collective atmosphere & "Kids need group work and face-to-face collaboration at school" \\
\hline & & Learning supports & "Teachers' direct guidance and supports are important and indispensable" \\
\hline & & School supervision & $\begin{array}{l}\text { "School offers a range of supervision services, such as school bus and lunch } \\
\text { service" }\end{array}$ \\
\hline & \multirow[t]{2}{*}{$\begin{array}{l}\text { Family } \\
\text { environment }\end{array}$} & Parental supervision & $\begin{array}{l}\text { "I still need to work during the epidemic, so I cannot supervise my kid's study at } \\
\text { home" }\end{array}$ \\
\hline & & Parent-child relationship & $\begin{array}{l}\text { "Staying at home causes trouble and contradictions. Using electronic products } \\
\text { too much also ruins the relationship between kids and adults" }\end{array}$ \\
\hline & \multirow{2}{*}{$\begin{array}{l}\text { Social } \\
\text { environment }\end{array}$} & Epidemic situation & "The current epidemic situation is still worrying." \\
\hline & & $\begin{array}{l}\text { Epidemic prevention and } \\
\text { control status }\end{array}$ & $\begin{array}{l}\text { "The epidemic prevention is sufficient, so we have confidence that the epidemic } \\
\text { is under control" }\end{array}$ \\
\hline
\end{tabular}

Table 2 Distribution of parents' willingness

\begin{tabular}{lllllll}
\hline Degree of willingness & Strongly willing & Quite willing & No tendency & Quite unwilling & Strongly unwilling & Total \\
\hline Amount $(\%)$ & $535(50.1)$ & $245(23.0)$ & $127(11.9)$ & $117(11.0)$ & $43(4.0)$ & $1067(100)$ \\
\hline
\end{tabular}

\section{Factors Influencing Parents' Willingness}

By dividing some of the questionnaires that mentioned multiple factors at the same time, we finally identified 1186 factors which influence parents' willingness from 1067 questionnaires, as shown in Table 3.

As can be seen from Table 3, with regard to factor appearance frequencies, $59.61 \%$ factors were related to personal issues, while $40.39 \%$ were related to environmental issues. The factors mentioned most frequently were "learning effectiveness," while the factor that was mentioned least was "family environment." Parents who have strong willingness considered "learning effectiveness" and "school environment" most. In contrast, for those who were strongly unwilling to send their children back to school, their attention focused mainly on "social environment" and "perceived epidemic safety."

\section{Factor Weighting Analysis}

The questionnaire used a 5-point Likert scale to judge the degree of parents' willingness to return their children to school, which gives the corresponding weight to each degree of parental willingness: $-2=$ "strongly unwilling," $-1=$ "Quite unwilling," $0=$ "No tendency," $1=$ "Quite willing," 2 = "Strongly willing." We calculated the average weight of each factor that represented parents' willingness to send their children back to school using the following function: 
$\bar{x}=\frac{\sum_{i=1}^{n} k \times x_{i}}{n}$

The weightings of factors influencing parents' willingness are shown in Fig. 1.

The personal factors accounted for an average weight of 1.26, and the environmental factors accounted for an average weight of 0.77 . Among these, the factors that make parents willing to let their children go back to school account for the vast majority, and the factors that make parents unwilling to let their children go back to school account for less than half. Some factors had large positive and negative weights at the same time (e.g., student safety and the epidemic situation), indicating that there are two extremes or uncertainties influencing parents' willingness, so its total impact interacted in swaying. With regard to the total weight, "mental health" had the greatest impact on willingness, while "trouble caused by epidemic prevention" had the greatest on unwillingness.

\section{Kruskal-Wallis H Test}

The Kruskal-Wallis $\mathrm{H}$ test was conducted on the personal factors and environmental factors separately to compare the effects of specific factors on parents' willingness. With respect to personal factors, $\mathrm{H}=264.13, p=0.000$, indicating that the overall difference between different factors of personal factors is statistically significant. The mean ranks of "intuitive expectation," "health issue," "learning effectiveness," and "perceived epidemic safety" were $441.22(n=86), 408.41(n=94), 391.90(n=415)$, and 100.94 ( $n=112)$, respectively. According to the analysis results in Fig. 1 and Table 4, it can be seen that the effects of "perceived epidemic safety" are opposite to others. "Intuitive expectation," "health issue," and "learning effectiveness" were driving forces, which can enhance parents' willingness to send their children back to school. In comparison, "perceived epidemic safety" was a restraining force.

With respect to environmental factors, $H=147.63$, $p=0.000$, the difference between different environmental factors was statistically significant. The mean ranks of "school environment," "family environment," and "social environment" were $314.60(n=169), 338.85(n=50)$, and $172.65(n=260)$, respectively. As can be seen in Fig. 1 and Table 4, the effect of "social environment" was opposite to that of "school environment" and "family environment." The former one was the restraining force hindering resuming classes, while the latter two were driving forces enhancing parents' willingness to send their children back to school.

\section{Field Model of Factors that Affect Parents' Willingness}

Through the content analysis of the questionnaire based on the Grounded Theory, we extracted the main factors affecting parents' willingness to send their children back to school. According to Field Theory, the factors that affect parents' wishes can be divided into two categories: personal factors and environmental factors, which interacted and composed the impact on parents' willingness. Through weight analysis of each factor and Kruskal-Wallis $H$ test analysis, it can be seen that "intuitive expectation," "health issue," "learning effectiveness," "school environment," and "family environment" were the driving forces of parents' willingness, whereas "perceived epidemic safety" and "social environment" were the restraining forces. According to these, a field model could be set up to interpret how the factors affect parents' willingness, as shown in Fig. 2.

Table 3 Frequencies of factors reported by parents with different degrees of willingness

\begin{tabular}{|c|c|c|c|c|c|c|c|}
\hline Categories & Factors & $\begin{array}{l}\text { Strongly } \\
\text { willing }\end{array}$ & $\begin{array}{l}\text { Quite } \\
\text { willing }\end{array}$ & $\begin{array}{l}\text { No } \\
\text { tendency }\end{array}$ & $\begin{array}{l}\text { Quite } \\
\text { unwilling }\end{array}$ & $\begin{array}{l}\text { Strongly } \\
\text { unwilling }\end{array}$ & Total $(\%)$ \\
\hline \multirow[t]{4}{*}{ Personal factors } & Intuitive expectation & 69 & 14 & 3 & 0 & 0 & $86(7.25)$ \\
\hline & Health issue & 66 & 22 & 5 & 0 & 1 & $94(7.93)$ \\
\hline & Learning effectiveness & 271 & 107 & 33 & 3 & 1 & $415(34.99)$ \\
\hline & $\begin{array}{l}\text { Perceived epidemic } \\
\text { safety }\end{array}$ & 6 & 15 & 27 & 44 & 20 & $112(9.44)$ \\
\hline \multirow{3}{*}{$\begin{array}{l}\text { Environmental } \\
\text { factors }\end{array}$} & School environment & 103 & 48 & 11 & 7 & 0 & $169(14.25)$ \\
\hline & Family environment & 35 & 13 & 2 & 0 & 0 & $50(4.22)$ \\
\hline & Social environment & 46 & 58 & 66 & 68 & 22 & $260(21.92)$ \\
\hline
\end{tabular}




\section{Discussion}

Resuming classes is not only an issue relevant to students' learning efficiency and physical and mental health, but also a serious social problem that warrants sufficient attention. Due to school closure or family confinement during the pandemic, physical harm, emotional impact, and sexual abuse suffered by students are also increasing (d'Orville, 2020; Lee, 2020; Ludvigsson, 2020). In this study, we found that the vast majority of parents were eager to let their children resume classes at school, while only $4 \%$ of parents argued against it. This is highly consistent with Qazi et al.'s (2020) study that reported the same willingness of parents. What are the problems with home-based study during the epidemic? What factors should be paid attention to when planning to resume classes? We aimed to find answers to the above questions from the parents' perspectives.

\section{Key Factors Influencing Parents' Willingness to Let Their Children Return to School}

A series of factors that influence parents' willingness were summarized in this study, including personal factors (i.e., intuitive expectation, health issue, learning effectiveness, perceived epidemic safety) and environmental factors (i.e., school environment, family environment, social environment). These factors are also believed to be the major reasons affecting students' learning and growth during the epidemic.

Parents believed that studying at home is not conducive to children's physical and mental health (such as affecting eyesight, irregular schedule, lack of physical exercise, etc.), but it also affects children's learning effectiveness (learning is not focused and systematic, etc.). These findings are consistent with some previous studies. For example, Yan et al. (2021) reported similar deficiencies caused by homebased learning (e.g., the eyestrain caused by staring at screens for a long time, poor course design, poor experience with online learning platforms). Kim also claimed that children generally spent less time on physical activities and gained weight during school closure (Kim et al., 2021). In addition, the process of studying at home, the lack of school environment support (such as a collective atmosphere, learning supports, school supervision), parent-child conflict in the family environment, and inadequate supervision by parents were also regarded as important factors affecting parents' judgment.

Moreover, children's health and safety are the most vital concerns when parents are considering whether to let their children return to school (Limbers, 2021; Tikkanen, 2019). Due to the epidemic situation in the social environment, some parents expressed their concerns about the ineffective prevention and control of the epidemic situation, and the lack of awareness and ability of students to prevent the spread of the virus. However, their overall willingness was

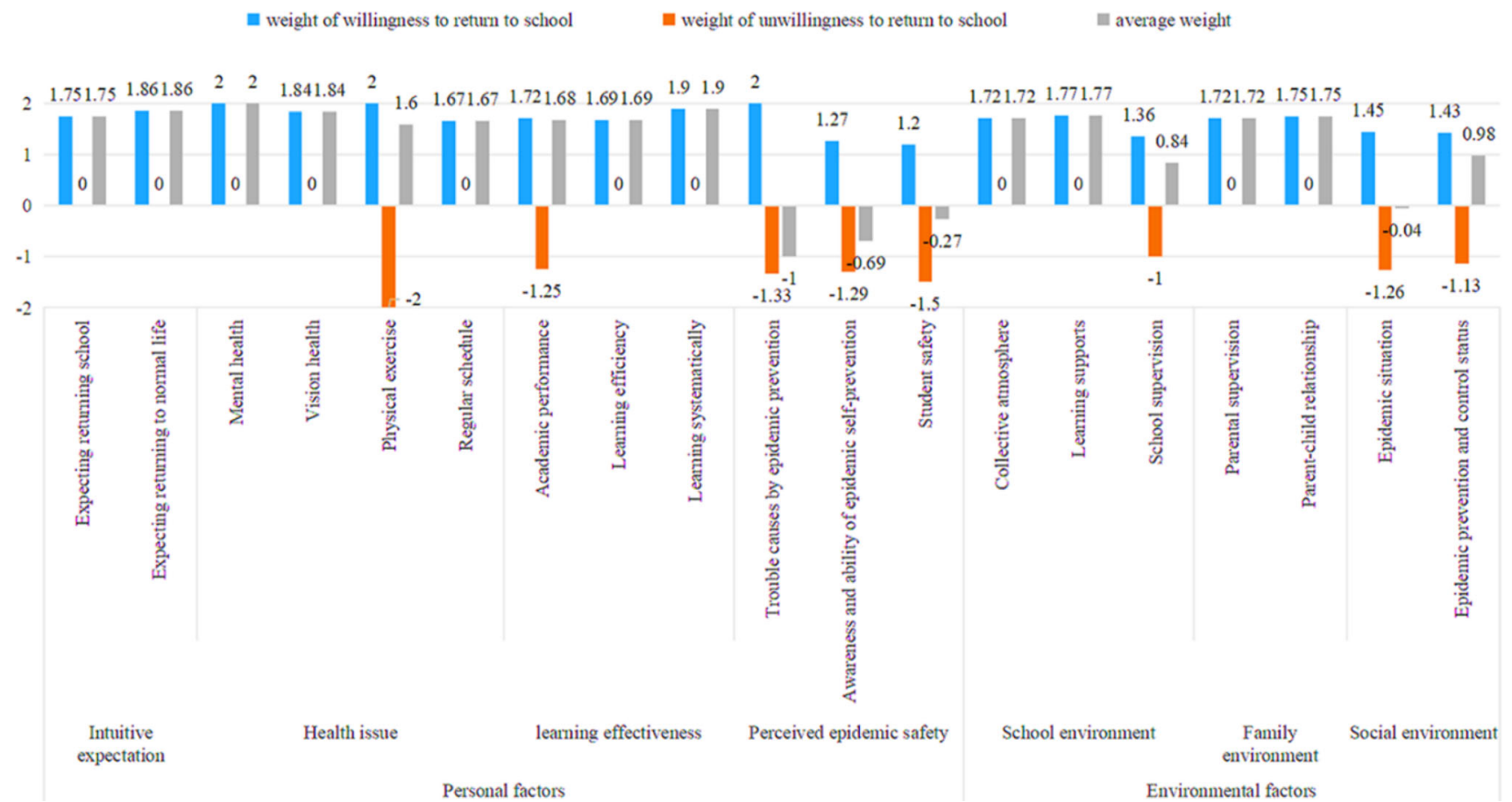

Fig. 1 Weightings of factors influencing parents' willingness. 2-Strongly willing, 1-Quite willing, 0-No tendency, - 1-Quite unwilling, and -2 - Strongly reluctant 
Table 4 Pairwise comparison of rank sum in factors

\begin{tabular}{|c|c|c|c|c|}
\hline Factor 1 & Factor 2 & Test statistic & Std error & Sig. \\
\hline \multicolumn{5}{|l|}{ Personal factors } \\
\hline \multirow[t]{3}{*}{ Intuitive expectation } & Health issue & -32.81 & 27.08 & 0.23 \\
\hline & Learning effectiveness & -49.33 & 21.50 & $0.02 *$ \\
\hline & Perceived epidemic safety & -340.28 & 26.02 & $0.00 * * *$ \\
\hline \multirow[t]{2}{*}{ Health issue } & Learning effectiveness & -16.52 & 20.73 & 0.43 \\
\hline & Perceived epidemic safety & -307.48 & 25.39 & $0.00 * * *$ \\
\hline Learning effectiveness & Perceived epidemic safety & -290.96 & 19.33 & $0.00 * * *$ \\
\hline \multicolumn{5}{|l|}{ Environmental factors } \\
\hline \multirow[t]{2}{*}{ School environment } & Family environment & -23.49 & 21.37 & 0.27 \\
\hline & Social environment & -141.95 & 13.11 & $0.00 * * *$ \\
\hline Family environment & Social environment & -165.44 & 20.50 & $0.00 * * *$ \\
\hline
\end{tabular}

$* p<0.05$

$* * * p<0.001$

still positive, which showed that the public has sufficient confidence in the epidemic prevention and control.

Based on the Field Theory, the psychological force that affects individual behavior is produced by the interaction between personal factors and environmental factors. As for personal factors, students need to raise awareness of the self-protection issues, and actively understand relevant means of epidemic prevention and control. On the other side of the coin, parents, schools, and society also need to provide sufficient supports to learners, pay attention to their physical and mental health, to the learning effects, and to other perspectives related to learners' development.

According to the Self-Determination Theory, only intrinsic motivation can have a positive influence on individuals (Deci \& Ryan, 2000; Zhan et al., 2021b). During the epidemic, the unprecedented changes and crises in the external environment affected learners' physical and mental health. Only by meeting their needs for autonomy (i.e., the psychological desire to take the initiative to be responsible for one's own decisions, choices and actions), competence (i.e., the belief that one's learning behavior or action can reach a certain level) and relatedness (i.e., the expectation of the inner desire to connect with others) can students achieve the best behavioral function and growth.

The behavior system of people and groups is generally in a relatively stable state called the "quasi-stationary equilibrium" state, which is affected by the driving forces and restraining forces, and reaches an in-between balance. This study shows that Field Theory can be used as an important basis to judge whether students should go back to school and resume classes during the epidemic, and that the threshold when the driving forces and restraining forces are equal can be taken as a critical point. If the driving forces are greater than the restraining forces, it may be a more appropriate choice to let students return to school to resume classes.

\section{Learning Effectiveness is the Most Critical Factor, and the Effect of Massive Online Education During the Epidemic is Not Satisfactory}

During the epidemic, the effect of students' home-based learning is largely determined by the quality of online supports. On the one hand, people believe that online learning has improved teaching efficiency, teachers' information literacy, and distance teaching skills (Huang \& Tang, 2020), and has improved learners' self-regulated learning ability $(\mathrm{Fu}, 2020)$. On the other hand, the poor effect of online education has aroused a great deal of criticism (Dong et al., 2020; Qazi et al., 2020). Most participants in this study claimed that online home-based education is not effective. As mentioned by the parents, the main problems of studying at home can be summarized as follows: (1) Due to limited guidance during home-based online learning, students learn fragmentally and superficially, without a systematic and complete cultivation of knowledge systems. (2) Home-based learning lacks a collaborative learning atmosphere with peers, the online teacher-student interaction is quite weak, parents' burden is too heavy, and they do not have sufficient ability to teach their own children, leading to distraction and difficulty in elaborating knowledge. (3) Long-term online learning causes myopia and the other health issues; therefore, most parents do not approve of online learning as an alternative to formal learning.

In order to make students study at home more effectively, the digital divide should be taken into account. Those who live in the backward areas might need supports 
Model diagram of factors affecting parents' willingness

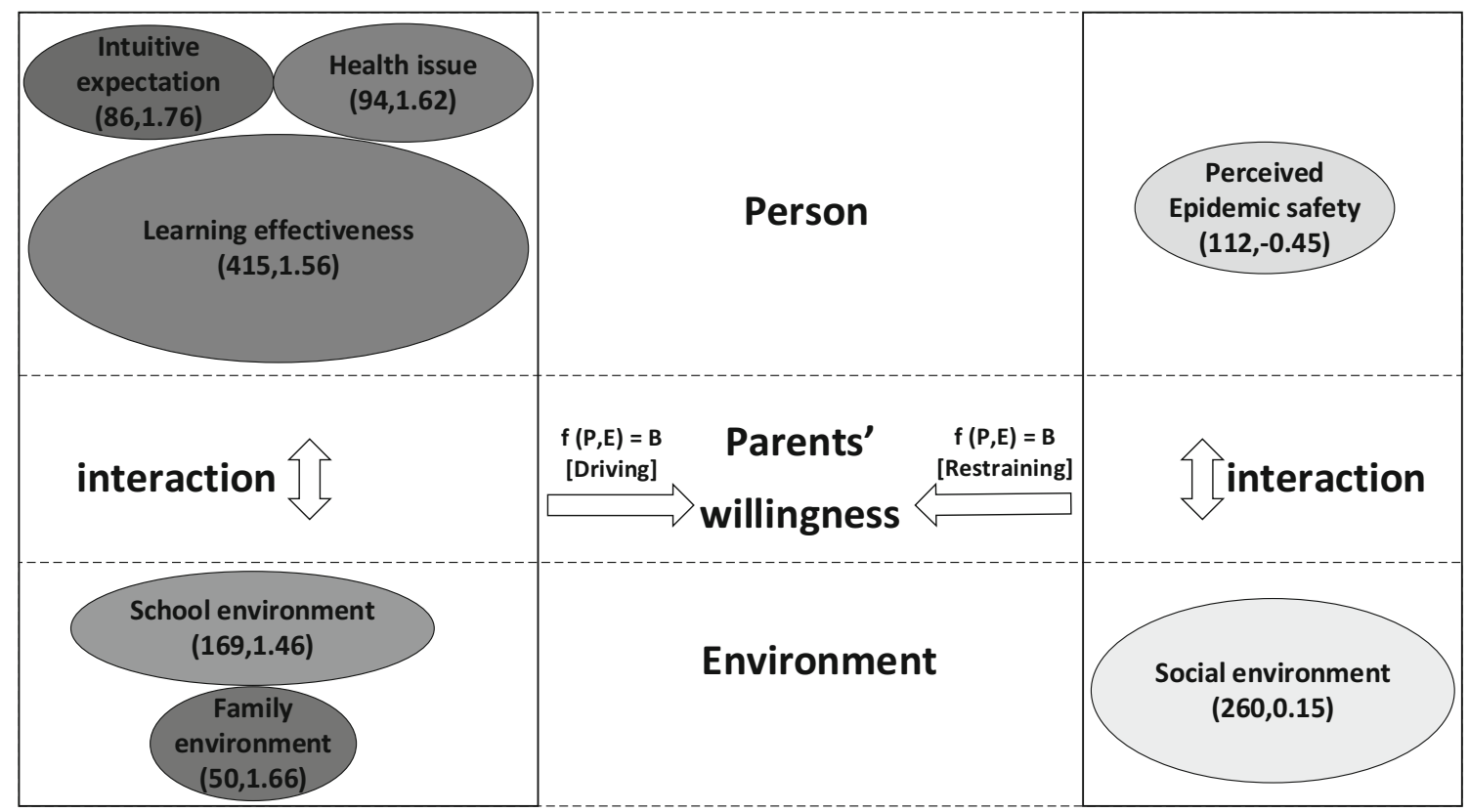

Fig. 2 Model diagram of factors affecting parents' willingness. The size of the circle in the figure represents the number of factors mentioned by parents. The larger the circle, the more times it is

in terms of network, software, and hardware infrastructure; thus, easily accessible courses such as TV broadcasting courses might be a good choice. It is also necessary to carry out teacher training in order to improve teachers' online teaching skills. Technical means such as online live classrooms and virtual laboratories are encouraged to be used actively for online supervision, evaluation, and interaction (Oliveira et al., 2020). The innovative teaching supports (e.g., web-on-demand teaching, TV and videobased teaching, and project-based family experiment exploration activities) are highly recommended (Chick et al., 2020) to enhance teacher-student interaction and to create an engaging online learning atmosphere (Iyengar, 2020). Zhan and Zhong (2020) put forward the suggestion of "flexible resumption of classes," suggesting multiple ways to offer flexible education and allow both homebased learning and face-to-face school-based learning to exist simultaneously.

\section{Students' Epidemic Awareness Should be Emphasized, and it is Necessary to Strengthen Students' Self-Protection Ability and Environment Protection Consciousness}

Hundreds of parents mentioned their concerns about their children's lack of ability to prevent the spread of epidemics and their lack of self-consciousness, such as "fearing that children will not be obedient to wear their masks mentioned by parents. The darker the color of the circle, the greater the absolute value representing the weight. The corresponding quantity and weight of each factor are also marked in the figure

properly." China has issued a series of Guidelines for the Prevention and Control of COVID-19 in Kindergartens and Secondary Schools (Peking university children and adolescentshealth research institute, 2020). The "Guidelines" pointed out that families and schools should cooperatively teach children and adolescents about imparting knowledge and skills of epidemic prevention, cultivating students' health habits and self-protection awareness. Knowledge related to the epidemic situation and skills of epidemic prevention can be introduced by sharing popular science books and scene simulations. Some schools in China took the epidemic as an opportunity to set up relevant life courses and science courses, guiding students to improve their self-protection ability, cherish life, and revere nature (Liu \& Wu, 2020).

\section{Students' Demands for a Social Atmosphere, Regular Schedule, and Environmental Supports from Schools, which can Hardly be Achieved by Home-Based Online Learning}

Parents worry that studying at home for a long time is not conducive to the children's regular work and rest, and cannot guarantee their physical exercise. The influence of long-term online education on their eyesight is also a worrying concern. Besides, students might more easily be exposed to some harmful information (e.g., pornography, violence, rumors, fake news), and it might also lead to 
game addiction, and cause other types of psychological harm and misconceptions (Zhan, 2021a). In addition, parents mentioned that the school's collective atmosphere and peer interactions are indispensable to students' development. The "three dimensions of learning and competence development" proposed by Illeris (2007) pointed out that learning is determined by the content knowledge, learning motivation, interaction in process, and the social environment that affects learning (Liang et al., 2020). Therefore, during the epidemic, we should pay attention to creating a good learning atmosphere and proper environment for children, and ensure their regular work and rest. It can be seen that online education cannot replace the social functions and provision of activity venues that school education can provide. Even if we have to adopt online education, sufficient effort should be made to increase learners' social presence, so as to ensure the quality of the education.

\section{Implications}

This study contributes to the literature by investigating the factors that concern parents when sending their children back to school after the COVID-19 outbreak and analyzed the dilemma that they were facing. Based on Grounded Theory and Field Theory, the key concerns from parents were categorized into personal factors and environmental factors, then further discussion was provided from the perspectives of school, family, and society. The added value of our work could be elaborated in two aspects: On the one hand, students' home-based learning effect and influence factors during the epidemic were summarized, and guidance was provided from the perspective of school, family, and society. On the other hand, the COVID-19 epidemic is a typical example of educational emergency issues. This paper explores the factors that parents were most concerned about when sending their children back to school after the COVID-19 outbreak, which provided common experience and lessons learned in the emergency context, and set up a potential direction for future reference.

The findings might be beneficial to several stakeholders: First, school teachers might get to know more about the situation when arranging the resumption of classes and get ready for the potential issues that are of most concern to parents. Second, family members would know more about other parents' concerns and could then adjust their judgment of the big picture and prepare for it. Third, the government could more comprehensively understand the situation of resuming classes and make decisions on promoting proper policies and further assisting effective class resumption. Fourth, this study explored the essential causes and solutions of the education crisis in the context of an education emergency, so as to provide effective guidance and new ideas for dealing with education emergencies in the future. The lessons learned can also benefit other countries which are still suffering from the epidemic and might meet the same situation when students resume classes. Last but not least, our findings can be generalized to other educational emergencies and have meaningful value in the fast-changing world with unexpected issues. No matter whether the COVID-19 epidemic disappears in the future or not, it is always necessary to be well prepared for educational emergency issues.

According to the Field Theory (Lewin, 1939), interaction between personal and environmental factors jointly influence individuals' behavior (Burnes \& Cooke, 2013). Personal factors have a greater impact and have been mentioned more frequently than environmental factors on parents' willingness to resume classes. More emphasis is placed on the internal motivation of individuals, while the external environment has a weak impact, which to some extent confirms the Self-determination Theory (Deci \& Ryan, 2000). With respect to driving forces, the personal factors (i.e., "intuitive expectation," "health issue," "learning effectiveness") and the environmental factors (i.e., "school environment," "family environment") contributed to parents' positive attitudes toward resuming classes. With respect to restraining forces, the personal factor of "perceived epidemic safety" and the environmental factor of "social environment" hindered parents' decisions to resume classes.

To reflect on our findings, students' effective learning requires not only the self-consciousness and the efforts of the learners themselves, but also the joint efforts of schools, families, and society. However, during the COVID-19 epidemic, or other special periods such as natural disasters or emergency situations, the effective links among school, family, and society were blocked. Then, students could only obtain support from one main aspect rather than all three, which might be the essential reason leading to the education crisis. For example, when students study at home during the epidemic, the responsibility of the family is highlighted, while the function of schools is shut down, which results in students having learning difficulties. Therefore, in order to ensure students' learning effectiveness during the educational emergency period, the key point is to overcome the problem brought by the interruption caused by emergencies, and strengthen the links among school, family, and society. If one of these three was weakened because of the emergency, the advantages of the other one should be reinforced and it should take responsibility for the missing party, so as to make up for the deficiency. It is also expected that the external power should step in and support the responsible parties to realize the educational function to the greatest 
extent. The missing party should also try its best to transform and optimize its own function by using suitable technical means.

The class resumption issue investigated in this study is actually a typical example of the joint effect of school,family, and society. After the COVID-19 outbreak, the family became the main place for students to learn during school closure. Therefore, home-based education should fully stimulate its own potential to support students' learning processes, and undertake part of the responsibility of school education. In this situation, parents' supervision and supports, and the relationship between parents and children are important (Xiao \& Song, 2020). In a survey conducted in China, more than half of the teachers believed that "parents' participation in online teaching is limited or very poor" (Limbers, 2021). As the main companions of students during the epidemic, parents should not only take the responsibility of "parents," but also play the role of "teachers" and "friends." Therefore, parents' workload also includes setting clear schedules for children, organizing home exercise activities, setting themselves as examples for children, educating children with care and patience, and helping children to monitor and manage themselves effectively. Collaborating with the community and social environment, parents can also hold face-to-face mutual assistance activities in order to create a learning atmosphere similar to schools.

As a major place for education, schools normally take major responsibility for students' learning. However, the school closure during the COVID-19 outbreak blocked the direct link between schools and students, which led to schools losing part of their functions. At this time, schools should take advantage of the Internet to offer online courses, online learning communities, and the other channels to actively provide students with learning supports and a learning atmosphere. If students choose to resume class after the outbreak, schools must take responsibility for strengthening the prevention of the epidemic. For example, teachers and students are organized to go to school and have lunch according to different schedules to reduce public gatherings, school equipment should be cleaned and disinfected frequently, and body temperature detection and identity verification should be routinely performed. In addition, schools should pay attention to various needs (e.g., online learning needs, psychological counseling needs, the desire for peer communication, etc.), and provide sufficient supports accordingly. Many parents felt frustrated when assisting children's learning at home; therefore, schools should also take action to form a good home-school communication and provide suitable guidance for parents either to assist students studying at home or to get used to the new school life.
With respect to the society, every citizen should take responsibility for reducing the risk and help to prevent and control the spread of the epidemic. Public efforts would help to control the epidemic and build up social confidence. Especially in the areas with insufficient government control, the society plays an important role in protecting the children's/youth's mental health status (Kim, 2020). For example, it would be beneficial to call on the public to wear masks consciously, avoid public gatherings, wash hands frequently, and so forth. In addition, it is also suggested to put forward some inclusive measures in education, community health, and social protection settings to support young people's healthy development (Arnove, 2020) and reduce the psychological and emotional harm caused by the epidemic.

Author Contributions ZZ and YL conceived the research conception and design. Material preparation and data collection were performed by ZZ, XY, and QC. Data analysis was performed by YL, XY, and QC. The first draft of the manuscript was written by ZZ, YL, and $\mathrm{XY}$ and all authors commented on previous versions of the manuscript. All authors read and approved the final manuscript.

Funding This study was financially supported by the Major basic research and applied research projects of Guangdong Education Department (Grant No. \#2017WZDXM004), Science and Technology Planning Project in Guangdong Province (Grant No. \#2020A1414050056).

\section{Declarations}

Conflict of interest The authors have no financial or proprietary interests in any material discussed in this article.

Ethical Approval All procedures performed in studies involving human participants were in accordance with the ethical standards of the institutional and/or national research committee and with the 1964 Helsinki Declaration and its later amendments or comparable ethical standards.

Consent to Participate Informed consent was obtained from all individual participants included in the study.

\section{References}

Argyris, C. (1997). Kurt Lewin award lecture, 1997-Field theory as a basis for scholarly consulting. Journal of Social Issues, 53(4), 811-827. https://doi.org/10.1111/0022-4537.00051

Arnove, R. F. (2020). Imagining what education can be post-COVID19. Prospects, 49(1), 43-46. https://doi.org/10.1007/s11125-020-09474-1

Back, K. W. (1992). This business of topology. Journal of Social Issues, 48(2), 51-66. https://doi.org/10.1111/j.1540-4560.1992.tb00883.x

Betz, C. L. (2020). COVID-19 and school return: The need and necessity. Journal of Pediatric Nursing, 54, A7-A9. https://doi.org/10.1016/j.pedn.2020.07.015 
Brager, G., \& Holloway, S. (1993). Assessing prospects for organizational change. Administration in Social Work, 16(3-4), 15-28. https://doi.org/10.1300/J147v16n03_02

Burnes, B. (2007). Kurt Lewin and the harwood studies: The foundations of OD. The Journal of Applied Behavioral Science, 43(2), 213-231. https://doi.org/10.1177/0021886306297004

Burnes, B., \& Cooke, B. (2012). Kurt Lewin's field theory: A review and re-evaluation. International Journal of Management Reviews. https://doi.org/10.1111/j.1468-2370.2012.00348.x

Burnes, B., \& Cooke, B. (2013). Kurt Lewin's field theory: A review and re-evaluation. International Journal of Management Reviews, 15(4), 408-425. https://doi.org/10.1111/j.1468-2370.2012.00348.x

Capurso, M., Dennis, J. L., Salmi, L. P., Parrino, C., \& Mazzeschi, C. (2020). Empowering children through school re-entry activities after the COVID-19. Continuity in Education, 1(1), 64-82. https://doi.org/10.5334/cie.17

Chick, R. C., Clifton, G. T., Peace, K. M., Propper, B. W., Hale, D. F., Alseidi, A. A., \& Vreeland, T. J. (2020). Using technology to maintain the education of residents during the COVID-19 pandemic. Journal of Surgical Education, 77(4), 729-732. https://doi.org/10.1016/j.jsurg.2020.03.018

Deci, E. L., \& Ryan, R. M. (2000). The 'what' and 'why' of goal pursuits: Human needs and the self-determination of behavior. Psychological Inquiry, 11(4), 227-268. https://doi.org/10.1207/s15327965pli1104_01

Dong, C., Cao, S., \& Liu, H. (2020). Young children's online learning during covid-19 pandemic: Chinese parents' beliefs and attitudes. Children and Youth Services Review. https://doi.org/10.1016/j.childyouth.2020.105440

d'Orville, H. (2020). COVID-19 causes unprecedented educational disruption: Is there a road towards a new normal? Prospects Quarterly Review of Comparative Education, 49, 1-5. https://doi.org/10.1007/s11125-020-09475-0

Downes, K. J., Danziger-Isakov, L. A., Cousino, M. K., Green, M., Michaels, M. G., Muller, W. J., Orscheln, R. C., Sharma, T. S., Statler, V. A., Wattier, R. L., \& Ardura, M. I. (2020). Return to school for pediatric solid organ transplant recipients in the United States during the coronavirus disease 2019 pandemic: Expert opinion on key considerations and best practices. Journal of the Pediatric Infectious Diseases Society, 9(5), 551-563. https://doi.org/10.1093/jpids/piaa095

Eysenck, H. J., \& Lewin, K. (1952). Field theory in social science. The British Journal of Sociology, 3(4), 371. https://doi.org/10.2307/586914

$\mathrm{Fu}$, W. D. (2020). Online teaching of primary and secondary schools teachers in China during the epidemic: Status, problems and strategies. Modern Education Management. https://doi.org/10.16697/j.1674-5485.2020.08.014

Garbacz, S. A., McIntyre, L. L., \& Santiago, R. T. (2016). Family involvement and parent-teacher relationships for students with autism spectrum disorders. School Psychology Quarterly, 31(4), 478-490. https://doi.org/10.1037/spq0000157

Hageman, J. R. (2020). Can students safely return to school in the age of COVID-19? Pediatric Annals, 49(9), e363-e364. https://doi.org/10.3928/19382359-20200818-01

Huang, W. \& Tang, C. (2020). Innovative application of informationbased education in primary and secondary schools in the postepidemic era: Beginner's mind, philosophy and path. China Educational Technology (12), 124-130. https://kns.cnki.net/kcms/detail/ detail.aspx ?FileName=ZDJY202012018\&DbName=CJFQ2020. Accessed 15 July 2021

Huang, R., Tlili, A., Chang, T.-W., Zhang, X., Nascimbeni, F., \& Burgos, D. (2020). Disrupted classes, undisrupted learning during COVID-19 outbreak in China: Application of open educational practices and resources. Smart Learning Environments, 7(1), 19. https://doi.org/10.1186/s40561-020-00125-8

Illeris, K. (2007). How we learn: Learning and non-learning in school and beyond (1st ed.). Routledge.

Iyengar, R. (2020). Education as the path to a sustainable recovery from COVID-19. Prospects, 49(1), 77-80. https://doi.org/10.1007/s11125-020-09488-9

Jiao, W. Y., Wang, L. N., Liu, J., Fang, S. F., Jiao, F. Y., PettoelloMantovani, M., \& Somekh, E. (2020). Behavioral and emotional disorders in children during the COVID-19 epidemic. The Journal of Pediatrics, 221, 264-266. https://doi.org/10.1016/j.jpeds.2020.03.013

Khattab, N., Abbas, A., Abbas, A.-R., \& Memon, S. F. (2020). Children returning to schools following COVID-19: A balance of probabilities-Letter to the Editor. International Journal of Surgery, 79, 202-203. https://doi.org/10.1016/j.ijsu.2020.05.084

Kidd, W., \& Murray, J. (2020). The Covid-19 pandemic and its effects on teacher education in England: How teacher educators moved practicum learning online. European Journal of Teacher Education, 43(4), 542-558. https://doi.org/10.1080/02619768.2020.1820480

Kim, J. (2020). Learning and teaching online during covid-19: Experiences of student teachers in an early childhood education practicum. International Journal of Early Childhood, 52(2), 145-158. https://doi.org/10.1007/s13158-020-00272-6

Kim, S. J., Lee, S., Han, H., Jung, J., Yang, S. J., \& Shin, Y. M. (2021). Parental mental health and children's behaviors and media usage during COVID-19-related school closures. Journal of Korean Medical Science, 36(25), 12. https://doi.org/10.3346/jkms.2021.36.e18

Lee, J. (2020). Mental health effects of school closures during COVID-19. The Lancet Child \& Adolescent Health, 4(6), 42. https://doi.org/10.1016/S2352-4642(20)30109-7

Lewin, K. (1939). Field theory and experiment in social psychology: Concepts and methods. American Journal of Sociology, 44, 868-896. https://doi.org/10.2307/2769418

Liang, L. M., Cai, J. D., \& Geng, Q. Q. (2020). Online teaching in primary and secondary schools under the epidemic situation: reality, improvement strategies and future reconstructionAnalysis based on learning perspective. e-Education Research, 41(05), 5-11. https://doi.org/10.13811/j.cnki.eer.2020.05.001s

Limbers, C. A. (2021). Factors associated with caregiver preferences for children's return to school during the COVID-19 pandemic. Journal of School Health, 91(1), 3-8. https://doi.org/10.1111/josh.12971

Liu, J. J., \& Wu, G. (2020). "Closing the city" without closing classes: Wuhan curriculum under the epidemic situation. Primary and secondary school management, (03), 46-47. https://kns.cnki.net/kns8/AdvSearch?dbprefix =SCDB\&\&crossD bcodes $=\mathrm{CJFQ} \% 2 \mathrm{CCDMD} \% 2 \mathrm{CCIPD} \% 2 \mathrm{CCCND} \% 2 \mathrm{CCISD} \% 2 \mathrm{C}$ SNAD\%2CBDZK\%2CCCVD\%2CCJFN\%2CCCJD. Accessed 15 July 2021

Ludvigsson, J. F. (2020). Systematic review of COVID-19 in children shows milder cases and a better prognosis than adults. Acta Paediatrica, 109(6), 1088-1095. https://doi.org/10.1111/apa.15270

Marrow, A. J. (1969). The practical theorist: The life and work of Kurt Lewin. Basic Books.

Oliveira, J. BAe., Gomes, M., \& Barcellos, T. (2020). Covid-19 and return to classes: Listening to the evidence. Assessment Assessment and Public Policies in Education, 28(108), 555-578. https://doi.org/10.1590/s0104-40362020002802885

Peking university children and adolescents health research institute (2020). COVID-19 prevention and control guidelines for kindergartens, primary and secondary schools were officially released. Chinese Journal of School Health, 41(04), 476. 
https://kns.cnki.net/kcms/detail/detail.aspx?FileName=XIWS 202004001\&DbName=DKFX202. Accessed 15 July 2021

Qazi, A., Naseer, K., Qazi, J., Alsalman, H., Naseem, U., Yang, S., Yang, S. Q., Hardaker, G., \& Gumaei, A. (2020). Conventional to online education during covid-19 pandemic: Do develop and underdeveloped nations cope alike. Children and Youth Services Review. https://doi.org/10.1016/j.childyouth.2020.105582

Strsuss, A., \& Corbin, J. (1998). Basics of qualitative research: Techniques and procedures for developing grounded theory. Sage Publications.

Tikkanen, J. (2019). Parental school satisfaction in the context of segregation of basic education in urban Finland. Nordic Journal of Studies in Educational Policy, 5(3), 165-179. https://doi.org/10.1080/20020317.2019.1688451

Xiao, L., \& Song, N. Q. (2020). Opportunities, challenges and coping strategy of online teaching for primary and secondary schools in ethnic areas-based on the big data analysis of Tibet, Xinjiang, Ningxia, Guizhou and Inner Mongolia. Journal of Tibet University, $35(04)$, 213-220. https://doi.org/10.16249/j.cnki.1005-5738.2020.04.029

Yan, L. X., Whitelock-Wainwright, A., Guan, Q. L., Wen, G. X., Gašević, D., \& Chen, G. L. (2021). Students' experience of online learning during the COVID-19 pandemic: A provincewide survey study. British Journal of Educational Technology. https://doi.org/10.1111/bjet.13102
Zhan, Z., \& Zhong, B. C. (2020). Flexible resumption of classes: providing flexibility for resumption of classes in post-epidemic period. Educator 18, 38-39. https://kns.cnki.net $/ \mathrm{kcms} /$ detail/detail.aspx?FileName $=$ JYJA202018016\&DbName $=$ CJFN 2020. Accessed 15 July 2021

Zhan, Z., Mei, H., Liang, T., Huo, L., Bonk, C., \& Hu, Q. (2021a). A longitudinal study into the effects of material incentives on knowledge-sharing networks and information lifecycles in an online forum. Interactive Learning Environments. https://doi.org/10.1080/10494820.2021.1897844

Zhan, Z., Wei, Q., \& Hong, J. C. (2021b). Cellphone addiction during the Covid-19 outbreak: How online social anxiety and cyber danger belief mediate the influence of personality. Computers in Human Behavior, 121, 106790. https://doi.org/10.1016/j.chb. 2021.106790

Zhong, B. C., \& Zhan, Z. H. (2020). Online learning makes school education sustainable during COVID-19 outbreak. Science. https://science.sciencemag.org/content/367/6482/1061/tab-e-letters. Accessed 15 July 2021

Publisher's Note Springer Nature remains neutral with regard to jurisdictional claims in published maps and institutional affiliations. 